\title{
Facebook: An Affinity Space for Young People's Environmental Learning and Action
}

\author{
Ellen Field
}

James Cook University

etropic 14.1 (2015): 72-83. http://www.reefandleaf.com.au/etropic.html \& http://www.jcu.edu.au/etropic

\begin{abstract}
This paper draws on my dissertation research, that is focused on elucidating the substance, structure, and dynamics of how youth are engaging in interest-driven environmental peer-to-peer learning and activism within social networking "affinity spaces”. Affinity spaces - virtual or physical - are locations where groups of people are drawn together because of an engagement or shared interest in a common activity (Gee, 2005). My research is situated within a constructivist research paradigm and employs ethnographic methods to gain "insider" understandings of teen social media practices that relate to environmental learning and action, as experienced by the teens themselves (Lankshear et al, 2011). Drawing upon data obtained from surveys, social media observation, and interviews with youth from 11 different interest-driven environmentally-focused Facebook groups, I will discuss variations of the networks and interactions. Specifically, I will explore the network structure and various interactional dynamics related to: scale of network, leadership, membership, and adult facilitators. Along with these findings, I will offer some recommendations for adult facilitators in regards to fostering environmental learning and action in youth-driven affinity spaces.
\end{abstract}

Keywords: environmental education; interest-driven learning; affinity spaces; social media; youth-driven

\section{Introduction}

In a recent paper on social networking sites and adolescent identity development, Reid and Boyer (2013, p. 251) write, "If education is directed at improving the ways in which we live and learn, should it not delve into one of its most influential sources?”

The rise of the internet and social networking sites are seen as drivers for the shift to $21^{\text {st }}$ century education. The design of a social networking site sets it apart from other interactive web applications because content is shared across networks of friendships rather than accessible to anyone and engagement is a central organizing characteristic. When an individual makes a post, it is personal because the individual feels it is important but it is also quasi-public because the friend network can read the post. This design feature is referred to as "object-centred sociality" (Engestrom, 2005) and it affords opportunities for people to share objects or artefacts (photos, videos, music, thoughts to broader social networks and in this process situate their ideas and values within a dynamic community that provides feedback and reciprocity (Owen et al, 2006). 
Amongst young people visiting a social networking site has been identified as the number one activity American youth do online: 81\% of youth internet users between the ages of $12-17$ use an online social networking site, whereas only $8 \%$ visit virtual worlds, such as Second Life (Pew Research Center's Internet \& American Life Teen-Parent Survey, July - September, 2012). For these youth, Facebook is the number one social networking site with $94 \%$ of youth internet users keeping a profile or account compared to $26 \%$ of youth internet users using twitter (Pew Research Center’s Internet \& American Life Teen-Parent Survey, July - September, 2012).

Within this paper, I draw upon Gee's notion of affinity spaces as locations where groups of people are drawn together because of a shared interest or engagement in a common activity (2005). He argues that affinity spaces are not communities of practice, as the notion of a community infers a sense of belongingness or close-knit ties amongst members rather in an affinity space the commonality is the social affiliation of a shared interest or engagement in a common activity that occurs in an online space. For example in a large Facebook group, members may or may not know each other. Gee argues that the notion of an affinity space "is a particularly important contemporary social configuration with implications for the future of schools and schooling” (2005, p. 214) because of the affordances of interest-driven learning.

The largest ethnographic study on youth internet engagement and informal learning, found that informal learning is either interest driven or friend-driven. The authors write "Our cases demonstrate that some of the drivers of self-motivated learning come not from the instutitonalized authorities in kids' lives setting standards and providing instruction, but from kids observing and communicating with people engaged in the same interests and in the same struggles for status and recognition that they are” (Ito et al, 2010, p. 22)

Within the literature, social networking sites are cited as facilitating many positive educational learning potentials such as: peer-to-peer learning, diversification of cultural expression, skill development for the modern workplace, a more empowered sense of citizenship (Jenkins et al, 2008), synchronous and asynchronous feedback, and the ability to augment social contexts, such as school, university, or local community (Mason \& Rennie, 2007). As such the conversational, collaborative, and community-like qualities of social networking sites are in alignment with "what we know to be good models of learning, in that they are collaborative and encourage participatory role for users” (Maloney, 2007 p. 26). Social networking sites can also support interactions and exchanges between learners facing similar challenges in their studies (Smith \& Peterson, 2007); connect learners with others who have shared interests and affinities not catered to in their immediate educational environments (Maloney, 2007). Young people are participating in these activities not only as individuals but often collaboratively and cooperatively as interestor purpose-driven groups (Marchant, 2007; Ito et al, 2010).

If social networking sites are connecting young people with others who have shared interests and affinities, then what affordances do these spaces offer in terms of informal peer-to-peer learning about environmental issues? Are young people engaging in peer-to-peer environmental learning within these spaces? Beyond learning, how do these spaces allow for expression of political identity on environmental issues? Do the connective affordances allow for young people to organize actions or coordinate events on environmental issues? 
Traditionally, environmental education within schools has focused on individual agency or private environmental actions, like turning off the lights (Chawla \& Cushing, 2007) and has focused far less on developing relational or transformative agency, for instance, the role of social movements and the politics and the development of collaborative skills and coalition building (Stevenson \& Stirling, 2010).

The importance of agency, critical thinking, and democratic practice can be traced through much scholarship on environmental education. Jensen and Schnack's notion of "action-competence" is described as the capacity to analyze society and life critically in order to understand the root causes of environmental problems, and to work for solutions to problems from both an individual and societal level (1997). They argue that environmental education programs often promote action-oriented learning; however, these programs can often be focused on disconnected activities focused on behaviour-modification rather than activities which promote action informed by critical analysis (1997). Furthermore Chawla and Cushing advocate for a political model of environmental education in order to give children and youth the opportunity to have direct experience in managing their school, engaging in community projects where they can see how mechanisms of government work and also feel that they are making meaningful contributions (2007).

Orr has also argued that environmental education is 'unavoidably political' and that educators and leaders need to decide if we "equip students morally and intellectually to be a part of the existing pattern of corporate-dominated resource flows, or to take part in reshaping these patterns towards greater sustainability” (Orr, 1992, pp. 145-6). Lastly, Education for Sustainability has been framed by agency, critical thinking, and democratic practice in the following way:

...a shared speculation with pupils on those forms of technology and social organisation which can enable people to live in harmony with one another and with the natural world. It should be a form of social education cast in what Giroux (1983) describes as the emancipatory mould. This seeks to empower pupils so to reflect on their experience in light of critical theory and to act on the insights gained. It is a form of praxis (Grundy, 1987) which by allowing pupils and teachers to reflectively deconstruct and reconstruct their social world, develops the critical and active citizens who are capable of bringing about the transition to sustainable development (Huckle, 1991, p. 54).

If environmental education and education for sustainability experts are advocating for a political and critical infusion in order for students to make meaningful contributions to transform environmental problems, and dominant education systems do not generally offer students these types of opportunities (Sterling, 1996), then are youth using their online social networks to engage in informal peer-to-peer learning or social organizing to create the kind of political and environmental change they hope to see in the world?

Within environmental education, understanding the impact of the Internet and Web 2.0 affordances, including social media, requires reimagining what constitutes environmental education and how it is practiced (Gough, 2009; Fawcett, 2009). My research is at the intersection of environmental and sustainability education, technology education, critical 
pedagogy, and youth social movements and relates to the burgeoning field of pedagogy centered around digital media production and socio-ecological learning (McKenzie et al, 2010), in which there is currently a deficit of primary research (Pickerill, 2003).

\section{Methodology}

Situating my research within a constructivist research paradigm, I have employed ethnographic methods because ethnography allows the researcher to investigate practices in the context of everyday life; offers the possibility of understanding various ways in which people construct meaning; and addresses the richness, and complexity of social life (Hammersly \& Atkinson, 1995). Ethnographic models, like many social science methodologies, are ever developing and adapting in response to epistemological tensions within research. Moreover, ethnographic practices are being challenged due to globalizing forces and telecommunications, which are rendering it increasingly difficult to isolate 'culture' to a bounded geography or set of cultural practices (Appadurai, 1996).

Within the 'crisis' of ethnography debates, my research draws upon methodologies developed within the field of virtual ethnography (Hine, 2000) and more specifically within networked ethnography (boyd, 2008; Burell, 2009). From a networked approach, my fieldwork was comprised of the many social networking sites which selected youth join to communicate and organize with their peers. This approach to a field site as a network allowed me to investigate the practices of teens who are using social media to share environmental information, coordinate events, and take political action. The intention has been to gain "insider" understandings of teen social media practices that relate to environmental learning and action, as experienced by the teens themselves (emic), rather than imposing an evaluative frame or meanings upon these practices (etic) from the outside or on the basis of generalizations that are presumed to be valid across a range of cultural contexts (Lankshear et al, 2011).

In 2012, I circulated a survey to numerous global youth environmental organizations and hubs. The survey invited 16 - 18 year olds who self-identify as social media users and that use social media to communicate about environmental issues to respond. The online survey resulted in collecting responses from 63 participants from 19 different countries (represented below). From the respondents, 14 youth volunteered to participate in a 3 month observation period, consisting of two interviews and monitoring environmental content posted to personal profile pages and groups. By the end of the observation period, I had interviewed 14 youth and monitored 11 environmental Facebook groups and pages administered by these youth. 


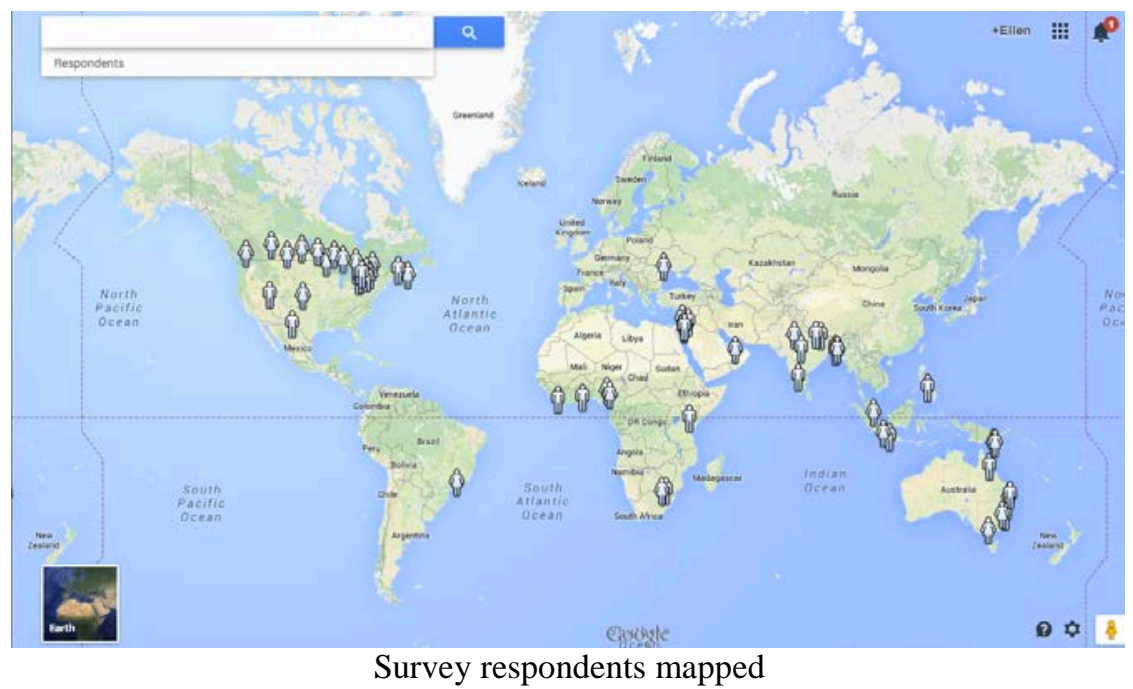

As my dissertation is focused on investigating the structure, substance, and dynamics of youth interest-driven environmental learning and action on social media, the findings within this paper are focused on structural representations of the Facebook groups that I have observed. I have used social network analysis (Carolan, 2014; Grunspan et al, 2014; Scott \& Carrington, 2011) to visualize several aspects of these groups: scale of network, leadership, membership and adult facilitators.

Specifically I have used NCapture, a browser plugin for Nvivo 10 to create database files that were then modified into node and edge files to be uploaded into Gephi, an open-source network analysis and visualization software package. Within Gephi, I rendered all the data visualizations using the same process following steps developed in the Gephi Quick Start user guide (2011). I have visualized the groups in two different ways: 1) friendship networks, which show number of "friends" or ties between members and 2) communication visualizations, which show the interactions between the authors of the post, individuals tagged in a post, and any subsequent commenters on the post. For all visualizations, the colour and size of the nodes show the centrality of the node to the network, through using degree functions within Gephi.

\section{Findings}

The network visualizations that have been developed (below) require contextual information, which will arise from qualitative analysis of interviews and content analysis of communication within participant Facebook groups and profiles to inform the substance and structure of learning and action within these youth-focused environmental Facebook groups. The visualizations are offered as a first phase of my analysis to consider the network structures and interactional dynamics related to: 1) scale of network 2) leadership 3) membership 4) adult facilitators

\section{$\underline{\text { Scale of network }}$}

This comparison is between two networks at different stages of development. 


\section{Sanosansar}

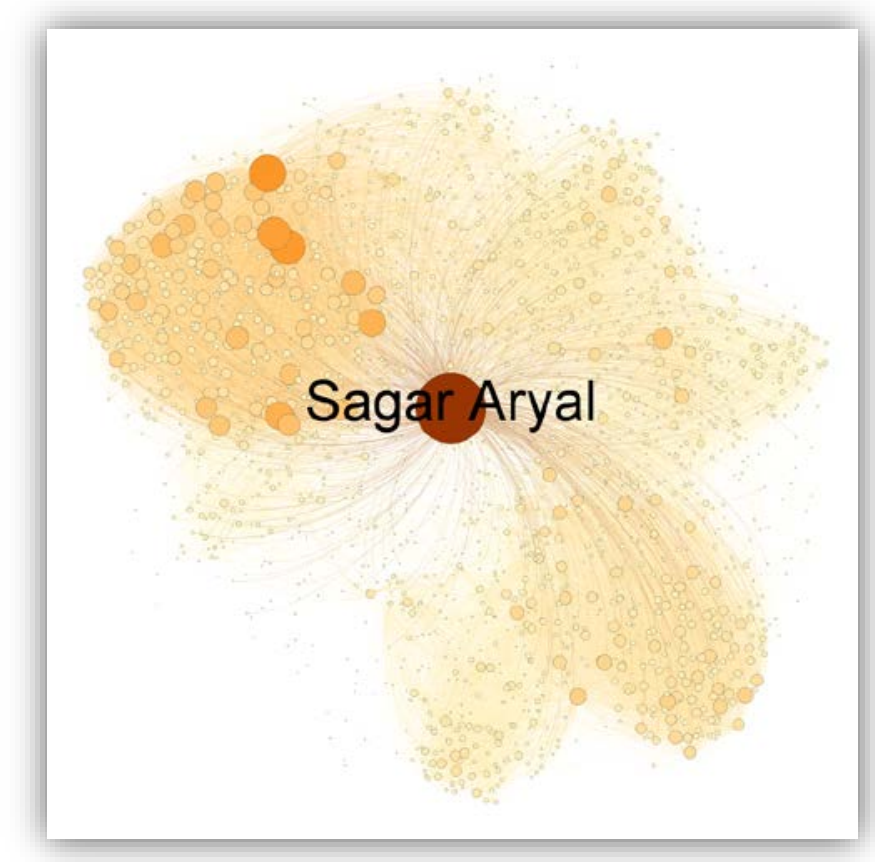

Anti-Fur Action Group
Sanosansar has existed in Nepal since Sagar Aryal was in $5^{\text {th }}$ grade (8 years ago) and runs programs and campaigns about social justice and environmental issues predominantly in Nepal. The organization has a web content management system that has 5000 members engaging on its platform and has over 2000 members in its public Facebook group (visualized above as a friendship network). Sagar is the central node with over 1600 connections in the network. The organization in the last year has started to work on an international level, by running programs with other youth organizations in India, Sri Lanka, Maldives, Germany, Nigeria, \& Sweden.

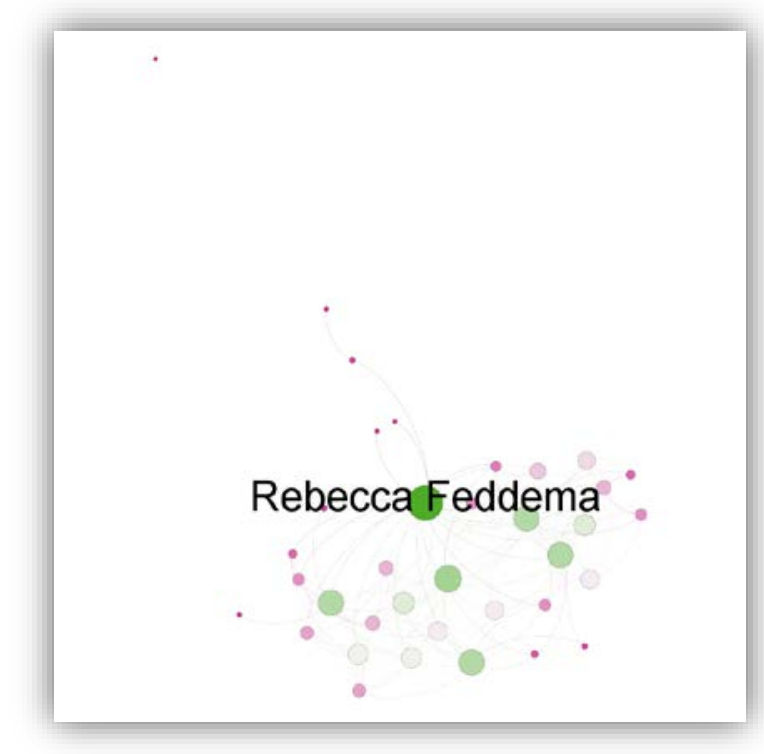

The Anti-fur Action Group started in late 2013 and has 47 members although the communication is almost entirely flowing from the administrator of the page, who is the founder and leader of the group. The group is in its beginning stages and does not have an active membership.

\section{Leadership}

The 14 respondents who participated in the observation period primarily perceive that they are "leaders" or "heavily involved" within an environmental Facebook group. 


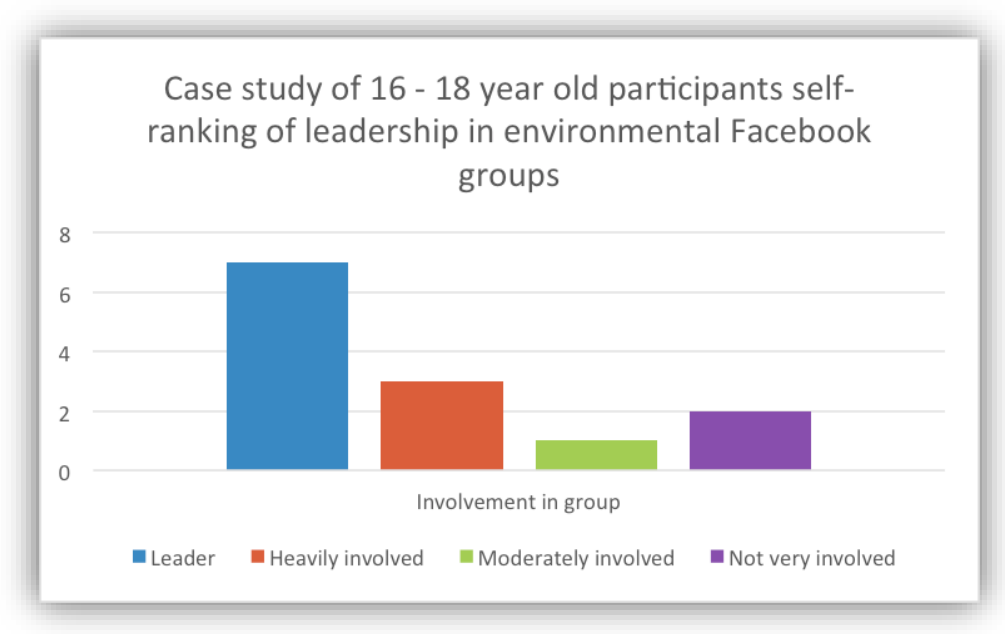

Interestingly, the two young people who selected "not very involved" are comprised of a conscientious objector who has real issue with the loss of privacy rights on social media and the other is a young woman who is looking to learn more about environmental issues and uses her page to share environmentally-related content to her friends but she did not know of any environmental Facebook groups that she could join that were interested in air pollution specifically in Jakarta.

\section{Peepal Plantation Project}

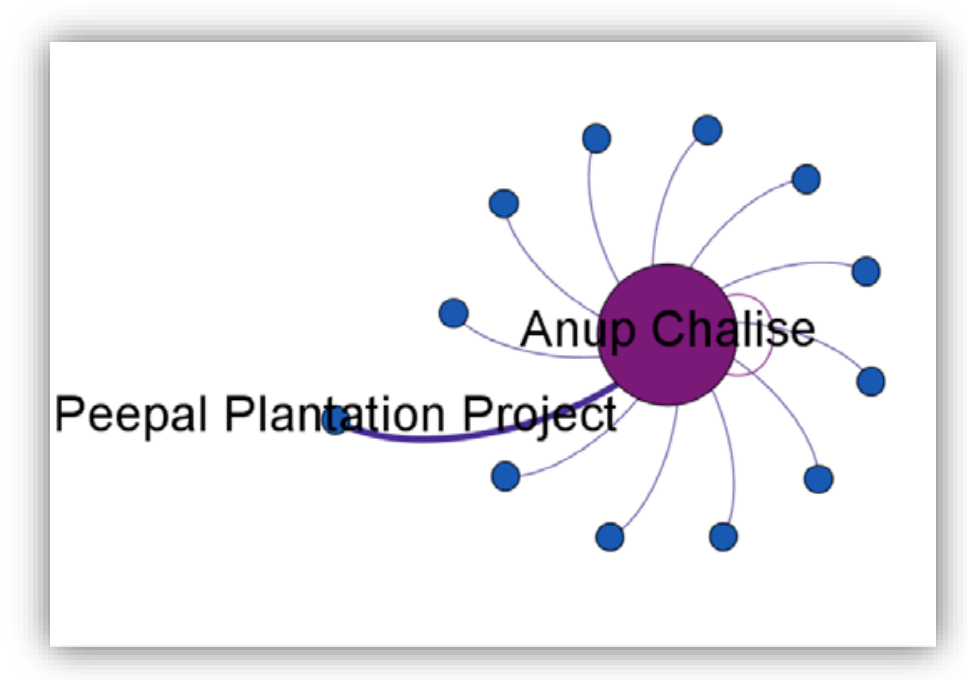

In 2009, when Anup was 14 he created the Peepal Plantation Project. The project has planted more than 3000 peepal trees in 14 districts in Nepal. The planting is coordinated by a youth group of volunteers who deliver training and tools to rural areas, and work directly with indigenous communities in these areas. The Peepal Project has delivered workshops to more than 2000 young people in Nepal. All planning, coordinating, planting and fundraising is youth-organized.

In this communication visualization, it looks as though Anup is the only leader. However the context of this group is very important to understand that how Anup organizes the group is through posting content on the Facebook group page but then when they need to organize a treeplanting event, they use Facebook chat (not captured) to discuss and organize amongst the 15 members. This is how Anup describes his leadership position: "My role in the group is to plan our works. Actually we don't have the kind of members who can plan a program. And so I do [the] planning 
works and when it comes to implementation. And if they are satisfied with it, then we work together as a group to make these ideas happen”

\section{TERRA}
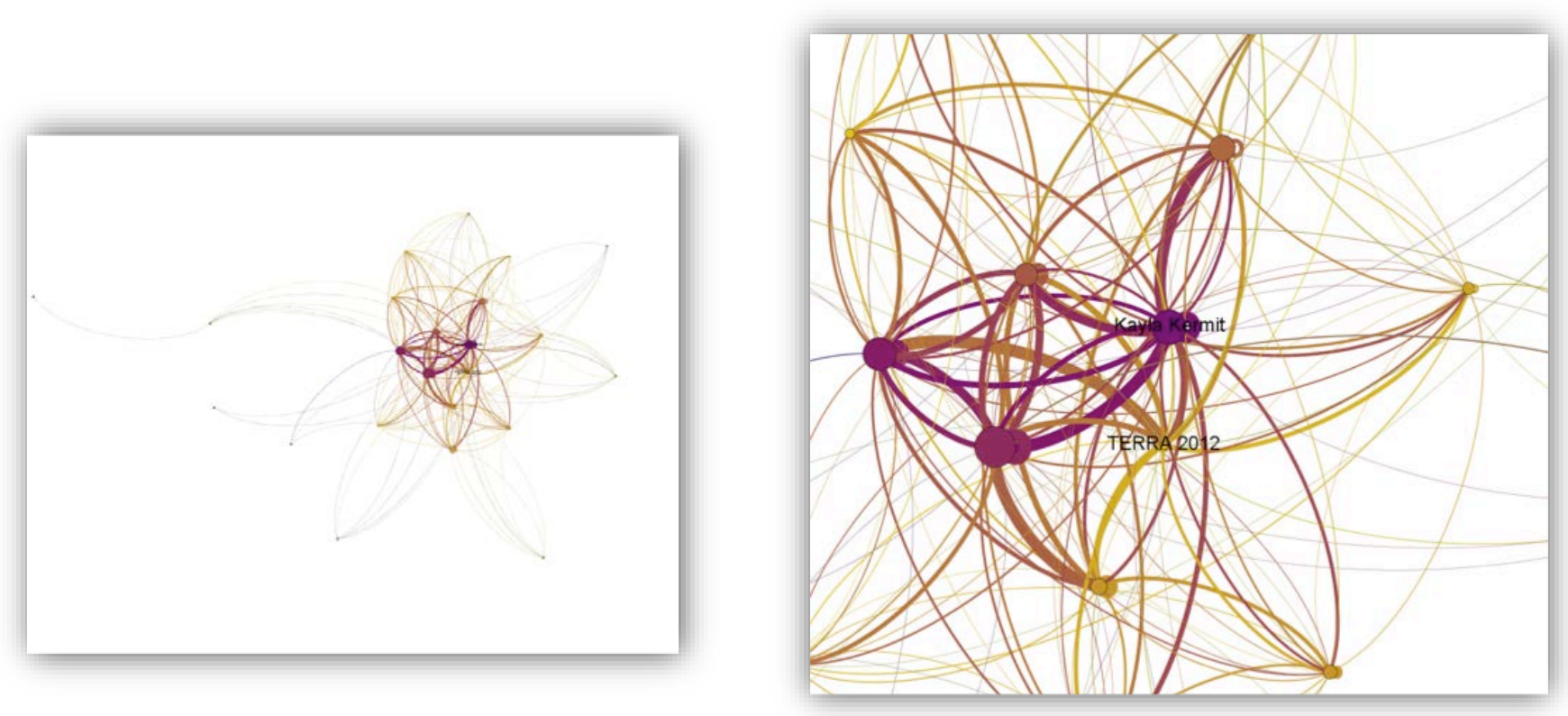

This communication visualization shows a very different model of leadership than the Peepal Plantation Project. This group, TERRA, went through a semester-long integrated environmental program at an Ontario high school in Canada. In Kayla’s words, “TERRA formed after we finished the program and we wanted to stay in touch. There are 20 of us and it is a closed group. We are all active all year on this page". The group is "used for sharing event information and coordinating participation in events". This example shows how groups that have strong preexisting friendship ties and group cohesion easily recreate that group structure in an online group space.

\section{Membership}

These two groups highlight group memberships at very different levels of development. 
Saviors of the Environment

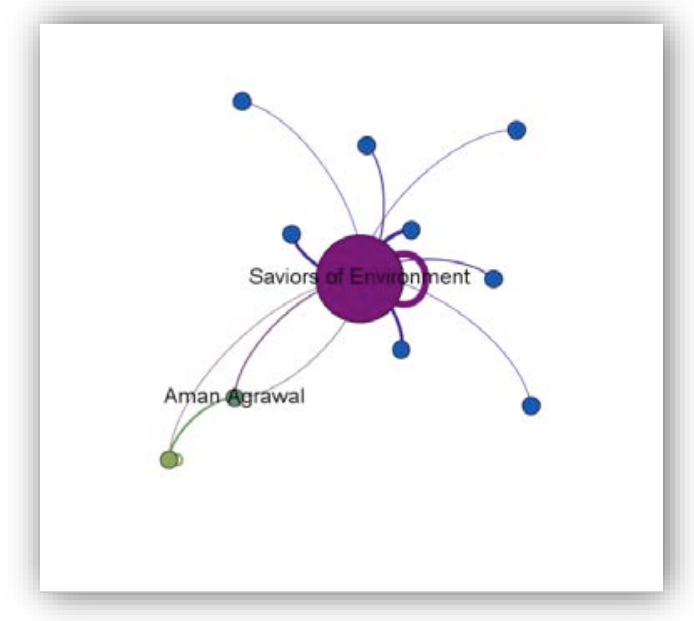

Saviors of the Environment founded by Aman Agrawal focuses on treeplanting projects in Northern India and has only existed for one year. Aman has been very busy over the last year with finishing his grade 12 year, his posts are sporadic to the page however the content is always very focused and dircted to purpose of the Saviors of the Environment group.

\section{Generation Earth}

Generation Earth is a well-established youth-created NGO in South Africa. It has regional leaders who organize weekly meetings and post regularly to this busy communication hub. The communication visualization shows how content flows through the network with the Generation Earth administrator, which is a shared login of several different highly-involved youth. The various bands of nodes in the visualization show that there are different levels of communication engagement. The most frequent contributors are closest to the centre based on the centrality functions used in Gephi. 


\section{$\underline{\text { Adult facilitators }}$}

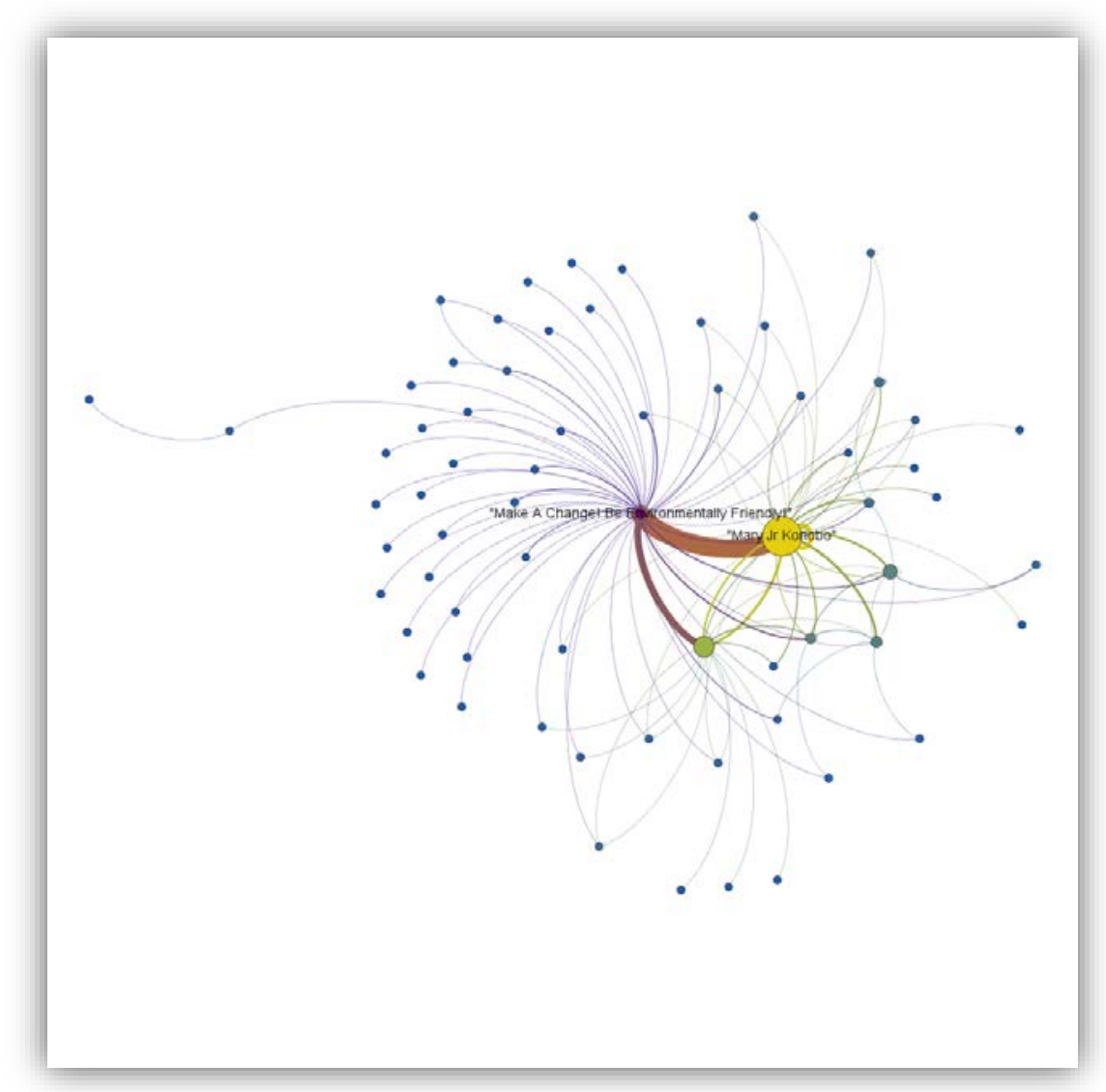

This visualization is of the Facebook page "Make A Change! Be Environmentally Friendly," a group that was started by Mary Konobo Jr. to help raise environmental awareness within the Port Moresby community. Mary invited her friends but needed to have 100 "fans" in order for the site to be searchable in a browser so she then invited her extensive family to participate. The page has provided an interesting forum for people to discuss community-issues outside of traditional conventions. Mary has said that without the Facebook page, she would not have discussed in a face-to-face conversaton litter in the streets or other issues with her elders unless they had brought up the topic. In many ways the platform has given Mary an avenue to raise issues to her elders in a way which does not break traditional conventions. In Mary's own words: "The significance of this group is that a conversation involving two people or more that has a very little chance of taking place in a face-to-face situation [but it] is able to take place in this group."

\section{Conclusion}

Preliminary findings from my research indicate the importance of Facebook affinity spaces for young people as spaces where they can meet and engage with like-minded and action-focused others in an informal way. The visualizations help to capture the networks in terms of the connections (in friendship networks) or interaction (in terms of communication visualizations). When we consider the public spaces that young people have available to them to meet and discuss issues of concern, like an oval, or public park, it is difficult to imagine that in these public 
spaces young people are meeting in a focused yet informal way to discuss environmental issues. However, through seeing the network visualizations, the importance of affinity spaces as spaces with powerful affordances for connection, collaboration, and action becomes evident. Social networking sites in this way do afford youth unparalleled opportunities to engage and collaborate with others who share similar environmental interests or concerns. Beyond the ability to connect with like-minded others, these networks show that within social networking sites are emerging affinity spaces that support social movement building (Facer, 2011), constitute new sites for citizenship (Lopez et al, 2006), and interest-driven and informal environmental learning (Ito et al, 2010).

\section{Works Cited}

Appardurai, A. (1996). Modernity at Large: cultural dimensions of globalization. Minneapolis, $\mathrm{MN}$ : Regents of the University of Minnesota.

boyd, d. (2008). Taken Out of Context. PhD in Information Management and Systems, University of California, Berkeley.

Burrell, J. (2009). The Field Site as a Network: A Strategy for Locating Ethnographic Research. Field Methods 21(2) pp.181-199 doi: 10.117/1525822X08329699

Carolan, B. (2014). Social Network Analysis and Education: Theory, Methods, and Application. Thousand Oaks: California, Sage.

Chawla, L., \& Cushing, D. F. (2007). Education for strategic environmental behavior. Environmental Education Research, 13(4), 437-452. doi: 10.1080/13504620701581539

Engestrom, J. (2005, 13, April). Why some social network services work and others don't - Or: The case for object-centered sociality [Blog post with comments]. Retrieved from www.zengestrom.com/blog/2005/04/why-some-social-network-services-work-and-othersdont-or-the-case-for-object-centered-sociality.html

Facer, K. (2011). Learning Futures: Education, Technology, and Social Change. New York, NY: Routledge.

Fawcett, L. (2009). Feral Sociality and (Un) Natural Histories: On Nomadic Ethics and Embodied Learning. In McKenzie, M., Hart, P., Bai, H., \& Jickling, B. (Eds.) Fields of Green: restorying culture, environment, and education (pp. 227 - 236). Cresskill, New Jersey: Hampton Press.

Gee, J. P. (2005). Semiotic Social Spaces and Affinity Spaces: From The Age of Mythology to Today's Schools. In Barton, D. Tusting, K. (Eds.) Beyond Communities of Practice: Language, Power, and Social Context (pp.214-232). Cambridge, UK: Cambridge University Press. doi: http://dx.doi.org/10.1017/CBO9780511610554.012

Gephi. (2010). Gephi Quick Start Tutorial. [slideshare]. Retrieved from: http://gephi.github.io/users/quick-start/

Gough, N. (2009). Becoming Transnational. In McKenzie, M., Hart, P., Bai, H., \& Jickling, B. (Eds.) Fields of Green: restorying culture, environment, and education (pp. 67 - 83). Cresskill, New Jersey: Hampton Press.

Grunspan, D., Wiggins, B., \& Goodreau, W., (2014). Understanding Classrooms through Social Network Analysis: A Primer for Social Network Analysis in Education Research. CBE Life Sci Educ, June 2, 2014, 167-178; doi:10.1187/cbe.13-08-0162

Hammersley, M. \& Atkinson, P. (2005). Ethnography: Principles in Practice $2^{\text {nd }}$ Edition. New York: NY: Routledge. 
Hine, C. (2000). Virtual Ethnography. Thousand Oaks, California: Sage.

Huckle, J. (1991). Education for sustainability: Assessing pathways to future. Australian Journal of Environmental Education, 7, (pp. 43- 62).

Ito, M., Baumer, S., Bittani, M., boyd, h., Cody, R., Herr-Stephenson, B.et al (2010). Hanging out, messing around, and geeking out : kids living and learning with new media. Cambridge, Mass: MIT Press.

Jenkins, H, Purushotma, R., Robison, A.; Weigel, M. (2008). Confronting the Challenges of Participatory Culture: Media Education for the 21st Century Building the New Field of Digital Media and Learning (pp. 72): MacArthur Foundation.

Jensen, B. Schnack, K. (1997). The action competence approach in environmental education. Journal of Environmental Education, 21(3), 163-178.

Lankshear, C., Leander, K., Knobel, M. (2011) Researching Online Practices. In B.Somekh \& C. Lewin (Eds) Theory and Methods in Social Research $2^{\text {nd }}$ Edition. Thousand Oaks, California: Sage.

Lopez M.H., Levine, P., Kiesa, A., Kirby, E. Marcelo, K. (2006). The Civic and Political Health of the Nation: a detailed look at how youth participate in politics and communities. Center for Information and Research on Civic Learning and Engagement. Retrieved from: http://www.civicyouth.org/PopUps/2006_CPHS_Report_update.pdf

McKenzie, M., Russell, C., Fawcett, L., \& Timmerman, N. (2010). Popular media, intersubjective learning, and cultural production. In Stevenson, R. \& Dillon, J. (Eds.), Environmental education: Learning, culture, and agency. Rotterdam: Sense Publications.

Mason, R., \& Rennie, F. (2007). Using Web 2.0 for learning in the community. The Internet and Higher Education, 10(3), 196-203. doi: 10.1016/j.iheduc.2007.06.003

Orr, D. (1992). Environmental Literacy: Education as if the Earth Mattered. $12^{\text {th }}$ Annual E.F. Schumacher Lecture.

Owen, M., Grant, L., Sayers, S., Facer, K. (2006). Opening Education: Social software and learning. Bristol, UK: FutureLab. Retrieved from: http://www2.futurelab.org.uk/resources/documents/opening_education/Social_Software_r eport.pdf

Pickerell, J. (2003). Cyberprotest: Environmental Activism Online. Manchester, UK: Manchester University Press.

Reid, G. \& Boyer, W. (2013). Social Network Sites and Young Adolescent Identity Development. Childhood Education, July-August, 2013. pp 244-253.

Scott, J., \& Carrington, P. (2011). The Sage Handbook of Social Network Analysis. Thousand Oaks, California: Sage.

Sterling, S. (1996). Education in change. In Huckle, J. \& Sterling, S. (Eds.) Education for Sustainability (pp. 18 - 39). London: Earthscan.

Stevenson, Bob, and Stirling, Carolyn (2010) Environmental learning and agency in diverse educational and cultural contexts. In: Stevenson, Robert B, and Dillon, Justin, (eds.) Engaging Environmental Education: Learning, Culture and Agency. Sense Publishers, Rotterdam, The Netherlands, pp. 219-237. 